Gregory S. Amacher*, Erkki Koskela** and Markku Ollikainen***

\title{
Deforestation, Production Intensity and Land Use Under Insecure Property Rights****
}

Department of Economics, University of Helsinki

Discussion Papers No. 589:2004

ISSN 1459-3696

ISBN 952-10-1519-5

January 12, 2004

* Department of Forestry, College of Natural Resources, 307 Cheatham Hall, Virginia Polytechnic Institute and State University, Blacksburg, VA 24060, USA. Email: gamacher@,vt.edu.

** Department of Economics, P.O. Box 17, FIN-00014 University of Helsinki, Finland, Email: erkki.koskela@helsinki.fi.

*** Department of Economics and Management, P.O. Box 27, FIN-00014 University of Helsinki, Finland. Email: markku.ollikainen@helsinki.fi.

**** Koskela thanks the Research Unit on Economic Structures and Growth (RUESG) at University of Helsinki and gratefully acknowledges the Academy of Finland, Yrjö Jahsson Foundation, Bank of Finland, and Nokia Group for financial support. Ollikainen thanks Academy of Finland for the grant No. 204476 for the position of Senior Researcher. 


\title{
Deforestation, Production Intensity and Land Use Under Insecure Property Rights
}

\begin{abstract}
:
We propose a framework with endogenous allocation of land between agricultural production, sustainable forest management, and unsustainable forest exploitation in the form of illegal logging to explore deforestation and agricultural and timber supplies when property rights are insecure. Uncertainty over property rights arises through risk of confiscation on sustainably-managed forest land, and through illegal logging activities on frontier native forest land. Confiscation risk is shown to increase deforestation by increasing both land conversion to agriculture and illegal logging. Contrary to current wisdom, we find that higher timber prices do not necessarily lead to an increase in the land used for sustainable forestry, because higher prices stimulate illegal logging activity. Increased monitoring and stronger enforcement reduce illegal logging, and thus deforestation. Confiscation risk decreases timber supply from unsustainable forestry practices while the affect of timber price on timber supply is ambiguous.
\end{abstract}

Keywords: deforestation, property rights, stochastic rotation

JEL classification: Q 223, Q15, K42.

\section{Introduction}


The last fifty years of research has made clear that land use plays a central role in deforestation. Exploitation of de facto open access native forests is known to follow rentdriven behavior, where land is converted into its most profitable uses. Most often tropical forests are converted to agriculture, which leads to permanent reductions in forest cover. It is worth noting that some native forests are developed into sustained plantation forests, which changes the type of forest present but does not entail deforestation per se (see, e.g. Anderson et al. 2002). Aside from land clearing, the most serious form of deforestation is illegal logging, either in the form of timber trespass on managed forests or unauthorized harvesting in native frontier forests (ITTO 2002). Illegal logging is exacerbated by an imperfect ability of governments to enforce land rights and policies. Gray (2000) argues that tropical frontier forests are illegally logged when marginal rent changes make this risky activity profitable.

Land use and management of forests are subject to many types of uncertainty, but insecure property rights are the most visible in developing countries. Conversion of native forest land to agricultural land is usually the only efficient means of securing private property rights to land, as open land is more easily protected. Sustainable forest plantations are a much more risky land use form, because forest land is not cleared and therefore not easily monitored. Moreover, Deacon (1994) argues that political instability results in periodic confiscation of land and forests.

Interaction of land use and insecure property rights jointly determines deforestation. Property right uncertainty affects both land allocated among alternative uses, and the production intensities chosen for a given land use. Our current understanding of the interaction of land use and insecure property rights is incomplete in many ways. Most of the land use literature abstracts from problems concerning insecure property rights, or it abstracts from the full set of important competing land uses. Notable exceptions are Mendelsohn (1994) and Armsberg (1998). In Mendelsohn (1994), forests are subject to confiscation unless costly effort is employed by the owner to defend forests from this risk. He shows that a probability of confiscation leads to reduced investment in management of forests. He focuses, however, mainly on incentives for destructive land use, with the sustainable forestry use treated in an exogenous manner. Armsberg (1998) considers production forestry and land clearing as 
potential uses across a classic von Thünen rent gradient. He provides support for modeling un-enforced property rights as risk of confiscation, but he does not consider confiscation risk explicitly.

Bohn and Deacon (2000) show how risk of capital confiscation reduces investment in sustainable uses of forest land. Their idea is that uncertainty regarding forest investment can arise in any period due to risk that forest rents could be confiscated. Bohn and Deacon do not, however, characterize land use or consider production intensity between competing uses. Parks et al. (1998) consider land use and margins between deforestation, agriculture and plantation forest uses. ${ }^{1}$ However, like the other papers, uncertainty regarding illegal logging and confiscation of sustainable forest rents are not addressed.

Our purpose in this paper is to examine competing land uses and production intensities for tropical developing economies when property rights are uncertain and affect agent's decision making. ${ }^{2}$ We extend the existing literature in several respects. First, we examine all relevant land use and production intensity choices, including unsustainable and sustainable forest uses. Second, we consider two forms of uncertainties pertaining to property rights. Uncertainty can arise through the possibility that forest rents can be confiscated before trees are harvested on land managed according to sustainable practices. Uncertainty also arises through a risk associated with illegal logging on the poorest quality land (frontier native forests and idle land). The latter is a case where harvesters face some probability of being detected and fined by the government. Both uncertainties are important owning to the government's inability to enforce property rights. Finally, we link timber supply to deforestation mechanisms.

Within this new framework, we investigate formally how various market and policy parameters affect deforestation. ${ }^{3}$ We find that results depend not only on how the

\footnotetext{
${ }^{1}$ Similarly, Barbier and Burgess (1997) study the socially optimal land use decisions between sustainable forest management and land clearing for crops. They demonstrate how amenities associated with forest stocks change the rent gradient in favor of less land clearing from a social perspective.

${ }^{2}$ It is worth noting that we focus here on a microeconomic study of deforestation, and this distinguishes our work from more macroeconomic studies that link deforestation to population change, changes in economywide interest and exchange rates, credit availability, or trade policies.

${ }^{3}$ This has been a point of debate within the literature. For example, Angelson (1999) and Angelson and Kaimowitz (1999) point out that previous models provide conflicting results concerning the effects of
} 
margins defining land use change, but also on how the production intensity within each land use changes. Most models have relied on the assumption that insecure property rights are captured simply through the possibility of land clearing for agriculture. However, we show that confiscation and illegal logging, both of which follow from insecure property rights, are much more complex determinants of deforestation. Supply has not been linked specifically to deforestation measures, yet it could be an easily observable indicator.

We demonstrate that confiscation risk increases deforestation by increasing both land conversion to agriculture and illegal logging. Contrary to current wisdom, higher timber prices do not necessarily lead to an increase in land used for sustainable forestry, because the profitability of illegal logging also increases. Confiscation risk decreases timber supply from unsustainable forestry practices, but the effect of timber price on timber supply is ambiguous. These findings have important policy implications. Reducing confiscation risk decreases deforestation via a twin-effect of reducing land conversion to agriculture and decreasing illegal logging. Any effort to reduce illegal logging via increased monitoring or higher penalty also is important in decreasing deforestation through channels: directly and via land shifting to sustainable forestry under more secure rights.

The rest of the paper is organized as follows. In section 2 we examine the choices of production intensity for each land use and characterize allocation of land among these uses. In Section 3 we study the qualitative determinants of land allocation and production intensities. In Section 4 we analyze the supply of agricultural products and supply of both sustainably- and unsustainably-harvested timber, and, finally, we offer some conclusions in Section 5.

\section{Production intensity and land allocation in agriculture and forestry}

tenure risk, and of timber prices in general on deforestation. Others have argued that increases in prices will lead to greater incentives for sustainable forest plantations (Barbier et al. 1995). 
We now detail a model of tropical deforestation and land use by assuming three possible uses of existing forest land. ${ }^{4}$ Agricultural production is practiced via clearing of forest land and is considered to be an efficient means of securing the property rights on the land..$^{5}$ Forest land use occurs in two forms, as sustainable and unsustainable forestry practices. With sustainable forestry, the landowner plants and harvests timber for long term rent maximization, making stand investments each time a new rotation is started. Tenure insecurity implies a risk that managed forest land will be confiscated before the landowner realizes rents during any rotation. Confiscation in the form of timber trespass can be total or partial. ${ }^{6}$ Unsustainable forestry practice is consistent with shorter term forest exploitation in the form of illegal logging. Because a land user harvests from what is perceived to be an exogenous stock, confiscation is not an issue. However, whether a harvester is detected illegally logging, and whether the government enforces a penalty for this activity once detection occurs, is important to decision making. Neither is guaranteed in tropical countries as others have noted (ITTO 2002, Gray 2000).

To model the distribution of land uses, we assume that existing forest land can be divided onto a continuum of parcels for which land quality is uniform on each parcel. These parcels vary in land quality. Landowners are price takers and face two types of decisions, first, how many parcels, should be devoted to each land use, and, second, what production intensity should be chosen for each parcel. The model is solved recursively using an approach modified from Lichtenberg (1989) and (2002), and Hardie and Parks (1997). Recursion means that agricultural and forestry production is first optimized over all parcels, and then each parcel is allocated to its most profitable use.

\subsection{Agricultural production}

\footnotetext{
${ }^{4}$ Hartwick et al. (2001) consider an intertemporal model where cycles develop as land is cleared for agriculture, but then is reconverted into forests sometime in the future as relative prices change. This idea applies more to developed countries, as the authors suggest, and it could be a long term feature of the basic deforestation problem we elaborate in this paper.

5 See e.g. Pendleton and Howe 2002 and Angelson (1999) for recent reviews of this literature as it is related to smallholders. Assuming property rights governing the agricultural land use are secure is consistent with the observation that clearing of land is seen as a way of protecting tenure on forest land, because trespass is easier to observe and deter (e.g. Armsberg 1998).

${ }^{6}$ Generally confiscation can take many forms, as pointed out by Bohn and Deacon (2000), including government expropriation as well as losses of investment from non-government sources, such as timber trespass.
} 
A landowner is assumed to employ variable agricultural inputs each period, represented by $l$, at a constant marginal cost of $w$. The landowner also pays a constant cost of conversion, denoted by $\psi$, whenever units of land are brought into agricultural production. Agricultural yield in each period is a concave function of the level of the variable input, i.e., $f(l ; q)$, where $f_{l}(l ; q)>0, f_{l l}(l ; q)<0$, and higher land quality q increases the marginal product of the input, $f_{l q}(l ; q)>0 .^{7}$ As is convention, we assume that there is no dependence between production in different periods. Using these assumptions, the present value of profit from agricultural production over all parcels is defined by,

$\pi=\int_{0}^{\infty}\left(p_{a} f(l ; q)-w l-\psi\right) e^{-r t} d t \quad \forall q$

where $p_{a}$ is the price of the agricultural crop and $r$ is the interest rate. The landowner optimizes agricultural production (1) by choosing the level of the input $l$ according to the first order condition, $p_{a} f_{l}(l ; q)-w=0$, which holds at each point in time. This implicitly determines the optimal level of $l$ in each time period, $\hat{l}^{*}=\hat{l}^{*}\left(p_{a}, w, q\right)$, and substituting this into (1) gives the indirect net present value profit function per parcel, $\pi^{*}\left(p_{a}, w, r, \psi, q\right)$, where we have indicated the marginal effects of the exogenous parameters making use of the envelope theorem.

\subsection{Sustainable timber production}

The sustainable forestry use is characterized by the landowner engaging in long term forest production. The best example of this would be managing successive rotations of

\footnotetext{
${ }^{7}$ In what follows, derivatives of functions with one variable will be denoted using primes, while partial derivatives will be denoted using subscripts indicating what variable we are differentiating with respect to.
} 
plantations. This is the case in many developing countries, such as in Latin America, where private land ownership abuts frontier native forests. Long term sustainable forest production is most conveniently described by a Faustmann model, where the landowner seeks to maximize the net present value of an infinite sequence of rotations by choosing rotation age. Establishment of plantations requires a management cost, which reflects planting effort and other efforts directed toward protecting one's investment, such as partial clearing around the perimeter.

Due to unenforceable property rights the Faustmann model must be modified to reflect the possibility of confiscation of forest land. Clearly, the possibility of confiscation represents some uncertainty that the landowner will lose rents from forest production during any one rotation, if confiscation occurs fully or partly before trees are harvested. A convenient way to capture this risk is to follow the forest fire uncertainty Faustmann model of Reed (1984), specifying uncertainty of confiscation as a Poisson process. Our approach differs from Reed (1984) in two respects. First, we will imbed such risk into a land use framework to assess how land use margins depend on uncertainty, and, second, we derive several qualitative results needed to understand the deforestation problem that have not been presented in this kind of rotation model.

Let forest yield be given by $F(T ; q)$, where $T$ is the rotation age, and $F_{T}(T ; q)>0, F_{q}(T ; q)>0$ and $F_{T q}(T ; q)>0$. The event of confiscation is random in each period and is described Poisson process having parameter $\lambda$, with an average arrival rate of confiscation in any time period equal to $1 / \lambda$. Given a rotation age of $T$, the probability that the forest is confiscated before the rotation age is reached is given by $\operatorname{Pr}(X<T)=1-e^{-\lambda T}$, and the probability that the rotation age is reached before confiscation occurs is given by $\operatorname{Pr}(X=T)=e^{-\lambda T}$.

We assume that the landowner is risk-neutral, which follows the existing rotation literature under uncertainty. The expected net present value per parcel, conditional on rotation age $T$, is,

$$
J=E\left\{\sum_{n=1}^{\infty} e^{-r\left(X_{1}+X_{2}+\ldots+X_{n}\right)} Y_{n}\right\}
$$


where $Y_{n}=0$ when confiscation occurs before the rotation age in any one rotation is reached, i.e., if $X_{n}<T$, and $Y_{n}=p_{f} F(T ; q) e^{-r T}-c$ if the rotation age is reached without confiscation, i.e., if $X_{n}=T$. The timber price net of harvesting costs is $p_{f}=\hat{p}_{f}-\phi$, where $\phi$ is the unit harvesting cost and $\hat{p}_{f}$ is the stumpage price, and $c$ is a cost of establishment once either the trees have been confiscated or the rotation age is reached. Our setup here means that confiscation is total when it occurs during a rotation, although we relax this later. This setup presumes that confiscation applies to the trees and not necessarily to the land. Thus, once confiscation does occur, the landowner then begins another forest rotation, and this process repeats each rotation forever under risk. This is consistent with timber trespass on sustainably managed forest land occurring because the government is unable to protect forests from this type of encroachment.

Given that confiscation events are assumed to arrive independently over time, we can rewrite the objective function in (2) as,

$$
J=\frac{E\left[e^{-r X}\left(p_{f} F(T ; q) e^{-r T}-c\right)\right]}{\left[1-E\left(e^{-r X}\right)\right]} .
$$

Evaluating the expectations, using procedures similar to Reed (1984), the objective function $J$ for the risk-neutral landowner over all parcels can be written in a convenient form as a function of confiscation risk and other parameters (see Appendix 1 for results that follow),

$J=\frac{(r+\lambda)\left[p_{f} F(T ; q) e^{-r T}-c\right] e^{-(r+\lambda) T}}{r\left(1-e^{-(r+\lambda) T}\right)} \forall q$

To find the first order condition for optimal rotation age we differentiate (4) with respect to $T$, which after some simplification becomes, 
$J_{T}=0 \Leftrightarrow p_{f} F_{T}(T ; q) e^{-r T}=r F(T, q) e^{-r T}+\frac{(r+\lambda)\left[p_{f} F(T ; q) e^{-r T}-c\right]}{\left(1-e^{-(r+\lambda) T}\right)}$.

We assume the second order condition, $J_{T T}<0$, holds. Equation (5), when compared to the deterministic case of $\lambda=0$, indicates that the opportunity cost of not harvesting increases, because the land rent component is now higher due to confiscation risk. This higher opportunity cost implies a shorter rotation age. Longer rotation ages increase the cumulative probability that confiscation will occur before the end of the rotation - thus, the presence of confiscation risk increases the expected cost of delaying harvest.

Given that the second order condition holds, we can substitute the optimal rotation age $T$ implicitly defined by (5) into the objective function (4) to obtain the expected indirect net present value rent per parcel from sustainable forest activities. It depends on exogenous parameters as follows $J^{*} \equiv J^{*}\left(\underset{+}{p_{f}}, c, r, \lambda, q\right)$. With the exception of timber price and land quality, other variables will have a negative effect on $J^{*}$.

The comparative statics of this type of model are not found in the literature. The following relationships hold between parameters and rotation age,

$$
\frac{\partial T}{\partial p_{f}}=-\frac{J_{T p_{f}}}{J_{T T}}<0 ; \frac{\partial T}{\partial c}=-\frac{J_{T c}}{J_{T T}}>0 ; \frac{\partial T}{\partial \lambda}=-\frac{J_{T \lambda}}{J_{T T}}<0 ; \frac{\partial T}{\partial q}=-\frac{J_{T q}}{J_{T T}}<0
$$

Higher timber price shortens the optimal rotation, but higher maintenance cost lengthens it. Increased confiscation risk reduces rotation age, because the expected cost of continuing any rotation, and thus losing rents to confiscation, is higher. Moreover, the higher is the quality of land, the shorter is the optimal rotation period.

The results in (6) are derived under the assumption that confiscation is total when it occurs. In the case of partial confiscation, the appendix shows that the expected net present value of sustainable forest production is higher, and the rotation age increases as the degree of confiscation decreases. Partial confiscation also does not change the qualitative results derived above under the assumption of total confiscation. 


\subsection{Unsustainable timber production}

Illegal logging is a form of unsustainable exploitation in de facto open access forests that are not directly protected by enforced property rights (Clarke et al. 1993, Boscolo and Vincent 2000, Amacher et al. 2003). Illegal logging can be modeled as rents captured by one time logging from an exogenously given stock of forests. When a harvester engages in this type of activity, he faces an uncertain prospect of being detected and paying a penalty for the illegal activity. ${ }^{8}$

To characterize this land use problem, we again assume risk neutrality. The expected present value of profits for unsustainable logging on all parcels is given by,

$$
V=\int_{0}^{\infty}\left[(1-\rho)\left(\hat{p}_{f} Q-\widetilde{c}(Q)\right)+\rho\left(\hat{p}_{f} Q(1-\tau)-\widetilde{c}(Q)\right)\right] e^{-r t} d t \quad \forall q
$$

where $Q$ is volume of forest logged, $\rho$ is the probability of detection by the government, and $\tau$ is the unit penalty assessed on revenues captured by the illegal harvester. The first term in (7) measures expected harvesting revenues in the absence of detection from illegal logging. The second term describes revenues net of the penalty when detection of illegal logging occurs and is enforced. The term $\widetilde{c}(Q)=\phi(q) c(Q)$ is a convex cost function for illegal logging. It depends positively on land quality, so that $\widetilde{c}_{q}=\phi^{\prime} c(Q)<0$. We can re-express the integral (7) as,

$$
V=\int_{0}^{\infty}\left[(1-\rho \tau)\left(\hat{p}_{f} Q-\widetilde{c}(Q)\right] e^{-r t} d t \quad \forall q\right.
$$

For the risk-neutral landowner, the first order condition for unsustainable forest production intensity (illegal logging) over all parcels is given by,

\footnotetext{
${ }^{8}$ Penalties are often low and detection is infrequent in developing countries, but this is simply a special case of the general form we introduce for unsustainable forest rent in (8).
} 
$V_{Q}=\hat{p}_{f}(1-\rho \tau)-\widetilde{c}^{\prime}(Q)=0$.

This shows that harvesting will occur so that expected per parcel marginal revenue equals the marginal cost of venturing out into frontier areas and illegally logging. Let optimal illegal logging equal $Q \equiv Q\left(\hat{p}_{f}, \tau, \rho\right)$. Substituting this into (8) gives the expected maximum rents captured by unsustainable forest harvesting: $V^{*} \equiv V^{*}\left(\hat{p}_{f}, \tau, \rho, \rho_{-}, q\right)$.

Higher timber price and higher quality of land will increase the expected present value for unsustainable harvesting, ceteris paribus, while a higher penalty rate, probability of detection, and higher interest rate will have the reverse effect.

The comparative statics of illegal logging are straightforward. An increase in timber price will increase unsustainable logging, $Q_{\hat{p}_{f}}>0$, while a higher penalty decreases it, $Q_{\tau}<0$. The same holds true for the probability of detection, $Q_{\rho}<0$. Since there is no dependence between periodic activities, the interest rate has no effect on logging for unsustainable activities.

\subsection{Land allocation between agriculture and forest uses}

We now examine how land is allocated between the three uses. To facilitate analysis, we start by making relevant assumptions about suitability of agriculture and the two forms of forestry on land of various qualities. Denote by $G$ the potentially usable amount of forest land. Within $G$ land quality differs depending on physical, chemical and biological factors, such as soil properties, hydrologic properties, etc. All land can be divided into separate parcels having uniform quality. Following Lichtenberg (1989), we rank land quality by the scalar measure $q$, with a scale chosen so that minimal land quality is zero and maximal land quality is equal to one, i.e., $0 \leq q \leq 1$. With this interpretation, $G(q)$ is simply defined as the cumulative distribution of $q$, i.e. the set of parcels having at most a quality level of $q$. Let $g(q)$ be the density function for $G(q)$, i.e, $g(q)=G^{\prime}(q)$.

The total amount of forest land is given by, 
$G=\int_{0}^{1} g(q) d q$.

The land area $\mathrm{G}$ will be allocated to agriculture and the two forestry uses or will remain idle. We showed earlier that $\pi_{q}^{*}>0, J_{q}^{*}>0$ and $V_{q}^{*}>0$, so any type of production is assumed to be more profitable on better land qualities. We now make the following assumption concerning relative profitability of land uses in terms of land quality.

Assumption A: For land qualities and land uses, the following relationships hold,

A1. $V^{*}<J^{*}<\pi^{*}$ for $q=1$,

A2. $V^{*}>J^{*}>\pi^{*}$ for $q=0$, and

A3. $V^{*}=0$ for $q=\bar{q} \geq 0$,

where A1 and A2 define the relative profitability of different land uses. From A1, at the best land quality level, agricultural production is most profitable, and sustainable timber production is more profitable than unsustainable illegal logging. A2 in turn indicates that the order is reversed on lowest quality land. Assumptions A1 - A2 together with $\pi_{q}^{*}>0$, $J_{q}^{*}>0$, and $V_{q}^{*}>0$ ensure that agriculture performs best when practiced on the highest quality land, ${ }^{9}$ and unsustainable forestry performs best when practiced on lowest quality land. This has been the observation in tropical countries where deforestation is studied (Parks et al. 1998). Finally, A3 allows for a possibility that some land will be left idle and not be allocated to forestry of any kind. This margin is defined by the zero profit condition of illegal logging (e.g., see Khanna et al. 2002 for a different application).

Denote land area devoted to agriculture and to combined unsustainable forestry and idle land by $L_{a}$ and $L_{m+i}$ respectively, so that land area devoted to sustainable forestry is then defined by $L_{f}=1-L_{m+i}-L_{a}$. Land area for unsustainable forestry $L_{m}$

\footnotetext{
${ }^{9}$ This could easily apply to either grazing or crop uses, as either are devoted to the highest quality land in tropical countries (Anderson et al. 2002).
} 
becomes defined by the zero-profit condition. Land allocation in the economy can be obtained by solving the following problem,

$$
\max _{L_{a}, L_{m+i}} P V=\int_{0}^{1}\left[V^{*} L_{m+i}+J^{*}\left(1-L_{m+i}-L_{a}\right)+\pi^{*} L_{a}\right] g(q) d q .
$$

The necessary conditions for interior solutions of $L_{a}$ and $L_{m+i}$ are respectively,

$$
\begin{aligned}
& \frac{\partial P V}{\partial L_{a}}=\pi^{*}-J^{*}=0, \\
& \frac{\partial P V}{\partial L_{m+i}}=V^{*}-J^{*}=0
\end{aligned}
$$

The first condition (12) defines the upper intensive margin of land quality between agriculture and sustainable forestry uses, which we denote as $q_{1}$. The second condition (13) defines the lower intensive margin between sustainable and unsustainable forestry, which will be denoted as $q_{2}$. Finally, the zero-profit condition

$V^{*}=0$

defines the extensive margin between unsustainable forestry and idle unexploited land, denoted by $\bar{q}$.

Under the assumption made above, interior solutions exist for land allocation. Thus, agriculture, sustainable forestry, and illegal logging will be conducted in three compact ranges of land qualities. Land devoted to agriculture and the two forms of forestry are defined using (10) and the definitions of three relevant margins as follows:

$$
L_{a}=\int_{q_{1}}^{1} g(q) d q=G(1)-G\left(q_{1}\right),
$$




$$
\begin{aligned}
& L_{f}=\int_{q_{2}}^{q_{1}} g(q) d q=G\left(q_{1}\right)-G\left(q_{2}\right), \text { and } \\
& L_{m}=\int_{\bar{q}}^{q_{2}} g(q) d q=G\left(q_{2}\right)-G(\bar{q}) .
\end{aligned}
$$

Land choices are illustrated in Figure 1 along with the rent curves of all land uses as a function of land quality. Land use is determined by the intersection of rent curves and by the zero-profit condition of unsustainable forest use. The figure reflects Assumption A, in that the rent gradient for the agriculture use, when graphed over land qualities, is steeper than the rent gradient for sustainable forestry use, and the rent gradient for sustainable forestry use is steeper than the rent gradient for unsustainable forestry use.

\section{Comparative statics of land allocation}

Now we examine what are the impacts of exogenous parameters on land allocation. We differentiate equations (15) - (17) with respect to exogenous variables, accounting for margins $q_{1}, q_{2}$, and $\bar{q}$ given by (12) - (14). Let the vector of exogenous variables be defined as a parameter $\theta$, i.e., $\theta=\left[p_{a}, p_{f}, c, r, \lambda, w, \rho, \tau\right]$, where $\hat{p}_{f}=\hat{p}_{f}-\phi$. Using this notation and differentiating we obtain,

$\frac{d L_{a}}{d \theta}=-g\left(q_{1}\right) \frac{\partial q_{1}}{\partial \theta}$,

$\frac{d L_{f}}{d \theta}=g\left(q_{1}\right) \frac{\partial q_{1}}{\partial \theta}-g\left(q_{2}\right) \frac{\partial q_{2}}{\partial \theta}$, and

$\frac{d L_{m}}{d \theta}=g\left(q_{2}\right) \frac{\partial q_{2}}{\partial \theta}-g(\bar{q}) \frac{\partial \bar{q}}{\partial \theta}$.

Equations (18) - (20) allow us to go beyond current literature, where most of the emphasis is placed on analyzing changes in land area devoted to agriculture (land clearing), or on analyzing only how the extensive margin changes with exogenous 
parameter changes. Here we concentrate on reporting overall effects of the parameters on the two types of forest uses.

\subsection{Sustainable forestry use}

We begin by reporting the overall effects on land area allocated to sustainable forestry. Equations (A2.1) and (A2.2) in Appendix 2 indicate how the upper and lower intensive margins behave with changes in the parameter vector $\theta$. These results reveal that agricultural parameters affect only the upper intensive margin $q_{1}$, i.e., the land use margin between sustainable forestry and agricultural land conversion, while parameters specific to unsustainable forestry affect only the lower intensive margin $q_{2}$, i.e., the land use decision between sustainable and unsustainable forestry.

The timber price, regeneration costs, risk of confiscation and the interest rate affect both upper and lower intensive margins, however. Consider first the effect of timber price on land devoted to sustainable forest production,

$\frac{d L_{f}}{d \hat{p}_{f}}=g\left(q_{1}\right) \frac{J_{\hat{p}_{f}}^{*}}{D}+g\left(q_{2}\right) \frac{V_{\hat{p}_{f}}^{*}-J_{\hat{p}_{f}}^{*}}{\Delta}=?$,

where $D=\left[\pi_{q}^{*}-J_{q}^{*}\right]>0$ evaluated at the upper intensive margin $q_{1}$, and $\Delta=V_{q}^{*}-J_{q}^{*}<0$ evaluated at the lower intensive margin $q_{2}$. A higher timber price increases the present value of timber revenues, so that the upper intensive margin increases, ceteris paribus. At the lower intensive margin, the sign of the difference $\left(V_{\hat{p}_{f}}^{*}-J_{\hat{p}_{f}}^{*}\right)$ depends on the sign of the expression $\widetilde{c}\left(Q^{*}\right)-\frac{[c+\phi F(T ; q)](r+\lambda) e^{-(r+\lambda) T^{*}}}{\left(1-e^{-(r+\lambda) T^{*}}\right)}$. The first term in this expression represents illegal logging costs, while the second term is a function of maintenance and harvest costs for sustainable forest production, as well as a function of the real interest rate and confiscation risk. In our general land use model, it is therefore not guaranteed that higher prices will result in greater incentives to establish sustainable forest plantations. If illegal logging costs are higher than the costs of sustainable forest 
production, then $\left(V_{\hat{p}_{f}}^{*}-J_{\hat{p}_{f}}^{*}\right)>0$ and the sign of $\frac{\partial L_{f}}{\partial \hat{p}_{f}}$ is ambiguous. If, however, the costs of illegal logging are lower than the costs of sustainable forestry as one would expect, then $\left(V_{\hat{p}_{f}}^{*}-J_{\hat{p}_{f}}^{*}\right)<0$. In this case, land in sustainable forestry is an increasing function of the price as some poorer quality land becomes relatively more profitable in sustainable forest use. This is more likely at higher interest rates and higher risks of confiscation, ceteris paribus. ${ }^{10}$ The effect of higher establishment or management costs on land parcels devoted to sustainable forestry is given by the following,

$$
\frac{d L_{f}}{d c}=g\left(q_{1}\right) \frac{J_{c}^{*}}{D}-g\left(q_{2}\right) \frac{J_{c}^{*}}{\Delta}<0
$$

A higher management cost decreases land rents for ongoing forest rotations, thereby reducing the profitability of sustainable forest production. Land clearing for agriculture becomes more profitable at the upper intensive margin, and thus lower quality land is cleared of forests. The lower intensive margin also changes, because some sustainable forest land is abandoned- it then becomes part of the unsustainable forestry use. Both margin effects reinforce each other and land area in sustainable forestry unambiguously decreases. This is illustrative of a double mechanism of deforestation, and it is one reason why some have called for subsidies to reduce costs of sustainable forest practices such as reduced impact logging (Winkler et al. 1997, Barreto et al. 1998).

The importance of confiscation risk to sustainable and unsustainable forest land uses has not been formally studied. Confiscation risk might promote illegal logging and reduce incentives to engage in sustainable forestry practices. Indeed, our land use model shows this to be the case. The effect of confiscation risk on land devoted to sustainable forest production is given by,

\footnotetext{
${ }^{10}$ This follows from defining $X=[c+\phi F()$.$] , and examining how the sustainable forestry cost term$ depends on the interest rate, i.e., $-\frac{\partial}{\partial r}\left[\frac{X(r+\lambda) e^{-(r+\lambda) T}}{\left(1-e^{-(r+\lambda) T}\right)}\right]=-X\left\{\frac{e^{-(r+\lambda) T}\left[1-e^{-(r+\lambda) T}-T(r+\lambda)\right]}{\left(1-e^{-(r+\lambda) T}\right)^{2}}\right\}$. Making use of a second order approximation for the term $\left(1-e^{-(r+\lambda) T}\right)$ (see Appendix 1) shows that the derivative is negative. A higher risk of confiscation has a similar effect.
} 


$$
\frac{d L_{f}}{d \lambda}=g\left(q_{1}\right) \frac{J_{\lambda}^{*}}{D}-g\left(q_{2}\right) \frac{J_{\lambda}^{*}}{\Delta}<0
$$

Increases in confiscation risk decrease the expected profitability of sustainable forestry relative to both agriculture and unsustainable forest practices, i.e. both the upper intensive and lower intensive margins move toward each other, and land devoted to sustainable forestry decreases.

An important policy parameter in developing economies is the interest rate. The effect of a real interest rate on land devoted to sustainable forestry is given by,

$$
\frac{d L_{f}}{d r}=g\left(q_{1}\right) \frac{\pi_{r}^{*}-J_{r}^{*}}{D}+g\left(q_{2}\right) \frac{J_{r}^{*}}{\Delta}=?
$$

Clearly, the fact that the interest rate affects both sustainable and unsustainable forest uses in qualitatively similar ways means that its effect on the different margins is unclear.

Finally, parameters affecting agricultural production are important to understanding determinants of deforestation, as subsidies for land conversion are known to encourage land clearing of native forests (see e.g. Angelson and Kaimowitz 1999). A summary of our results related to this are as follows,

$$
\frac{d L_{f}}{d p_{a}}=-g\left(q_{1}\right) \frac{\pi_{p_{a}}^{*}}{D}<0 ; \frac{d L_{f}}{d \psi}=-g\left(q_{1}\right) \frac{\pi_{\psi}^{*}}{D}>0 ; \text { and } \frac{d L_{f}}{d w}=-g\left(q_{1}\right) \frac{\pi_{w}^{*}}{D}>0
$$

Interpretations are straightforward. Higher prices and costs in agriculture affect only the upper intensive margin. A higher price (clearing and input cost) increases (decreases) profitability of agriculture relative to forestry, and thus the upper intensive margin shifts to lower (higher) land qualities. The result of this is a corresponding change in forest land area devoted to sustainable forestry. We find something new, namely that while agricultural supports reduce land allocated to sustainable forestry, they have no effect on 
the extensive margin and therefore do not affect the amount of land exploited for unsustainable forestry uses such as illegal logging.

\subsection{Unsustainable forestry use}

Turning to the question of how various parameters affect land area allocated to unsustainable forestry use, we find that the effects of important parameters are given by,

$$
\begin{aligned}
& \frac{d L_{m}}{d \hat{p}_{f}}=-g\left(q_{2}\right) \frac{V_{\hat{p}_{f}}^{*}-J_{\hat{p}_{f}}^{*}}{\Delta}+g(\bar{q}) \frac{Q(1-\rho \tau)}{V_{q}^{*}}=? \\
& \frac{d L_{m}}{d \rho}=-g(\bar{q}) \frac{\hat{p}_{f} \tau Q}{V_{q}^{*}}<0 ; \frac{d L_{m}}{d \tau}=-g(\bar{q}) \frac{\hat{p}_{f} \rho Q}{V_{q}^{*}}<0,
\end{aligned}
$$

As for the effect of timber price, we have a similar situation as we did before with sustainable forest land area. That is, the sign of (26) depends on the difference in cost structures between sustainable forest management and illegal logging in the first term, which governs the effect of prices on the lower intensive margin $q_{2}$. The second RHS term is the effect of price on the extensive margin realized through changes in the profitability of illegal logging - this is a positive function of the price. If costs of illegal logging are higher than the costs of sustainable forest production, then the area subject to illegal logging is an unambiguously increasing function of the price given that $\left(V_{\hat{p}_{f}}^{*}-J_{\hat{p}_{f}}^{*}\right)>0$ in $(26)$.

According to (27), a higher probability of detection, or a higher enforced fine for illegal logging, will decrease the profitability of unsustainable activities. This implies governments must find ways to enforce illegal logging and collect stiff fines for such behavior, if the goal is to reduce area subjected to this use. Doing so decreases profit from illegal logging, thereby shifting the external margin on better land qualities and reducing deforestation.

\section{Agricultural and timber supplies}


One advantage of our land use model is that we can determine how timber and agricultural supplies shift in an economy, as either margins between different land uses shift or production intensities change in response to exogenous paramters. The supply effects of market parameters are rarely discussed in the literature, and supply has not been linked specifically to deforestation mechanisms. This merits investigation, because timber supply is an observable indicator of production and thus a potential target for policies.

The earlier results concerning margins indicate how land area responds to changes in the parameter vector $\theta$. Supply effects of $\theta$ are equivalent to changes in production intensity and land area devoted to each forest use. Prior to examining these effects, we must first define a per parcel supply function for each practice and an aggregate supply function over all parcels devoted to each practice. We will do this for one point in time, but the analysis holds over time as long as parameters remain constant.

\subsection{Timber supply from sustainable forestry}

Denote the supply of wood from sustainable forestry land as $S_{f}$. Because the sustainable forestry segment of our model follows the common rotations-based approach, we employ the conventional definition of annual average supply for these models (e.g, Clark 1976, pp. 262-263, Conrad 1999, pp. 68-70). Average annual timber supply per parcel is defined by

$Q_{f}^{*} \equiv Q_{f}^{*}\left(T^{*} ; q\right) \equiv \frac{F\left(T^{*} ; q\right)}{T^{*}}$.

Aggregate average annual timber supply is then given by,

$$
S_{f}=\int_{q_{2}}^{q_{1}} Q_{f}^{*} g(q) d q .
$$


It is now straightforward to investigate how various parameters change the supply function in (29) by totally differentiating with respect to parameters in $\theta,^{11}$

$$
\begin{aligned}
& \frac{d S_{f}}{d \hat{p}_{f}}=\int_{q_{2}}^{q_{1}} \underbrace{\frac{\partial Q_{f}^{*}}{\partial \hat{p}_{f}}}_{-} g(q) d q+Q_{f}^{*}\left(q_{1}\right) \underbrace{\frac{\partial q_{1}}{\partial \hat{p}_{f}}}_{+}-Q_{f}^{*}\left(q_{2}\right) \underbrace{\frac{\partial q_{2}}{\partial \hat{p}_{f}}}_{?}=?, \\
& \frac{d S_{f}}{d c}=\int_{q_{2}}^{q_{1}} \underbrace{\frac{\partial Q_{f}^{*}}{\partial c}}_{+} g(q) d q+Q_{f}^{*}\left(q_{1}\right) \underbrace{\frac{\partial q_{1}}{\partial c}}_{-}-Q_{f}^{*}\left(q_{2}\right) \underbrace{\frac{\partial q_{2}}{\partial c}}_{+}=?, \\
& \frac{d S_{f}}{d r}=\int_{q_{2}}^{\underbrace{q_{1}}} \underbrace{\frac{\partial Q_{f}^{*}}{\partial r}}_{-} g(q) d q+Q_{f}^{*}\left(q_{1}\right) \underbrace{\frac{\partial q_{1}}{\partial r}}_{?}-Q_{f}^{*}\left(q_{2}\right) \underbrace{\frac{\partial q_{2}}{\partial r}}_{?}=?, \text { and } \\
& \frac{d S_{f}}{d \lambda}=\int_{q_{2}}^{q_{1}} \underbrace{\frac{\partial Q_{f}^{*}}{\partial \lambda}}_{-} g(q) d q+Q_{f}^{*}\left(q_{1}\right) \underbrace{\frac{\partial q_{1}}{\partial \lambda}}_{-}-Q_{f}^{*}\left(q_{2}\right) \underbrace{\frac{\partial q_{2}}{\partial \lambda}<0 .}_{+}
\end{aligned}
$$

The most interesting, and indeed the only clear result, concerns the impact on sustainable timber supply of confiscation risk (equation 33). Higher confiscation risk unambiguously reduces timber supply from sustainable forestry. This arises through two channels: a) changes in margins (upper intensive and lower intensive) that decrease total land area in sustainable forestry via the second and third RHS terms; and b) production intensity decreases on all parcels devoted to sustainable forestry as risk of confiscation increases. Thus, timber supply decreases unambiguously, and deforestation increases because of illegal logging and agricultural land clearing.

The effects of other parameters on timber supply from the sustainable forest practice are not as clear. From equation (30), a higher timber price induces expansion of sustainable forest use to higher quality parcels currently devoted to agriculture, but its effect on the lower intensive margin remains ambiguous. Moreover, higher timber price

\footnotetext{
${ }^{11}$ The first terms in (30) - (33) measure the change in timber production intensity from a parameter change, i.e. these measure rotation age changes. For any exogenous parameter $\theta$, a change in average annual timber supply is given by $\frac{T_{\theta}}{T}\left[F^{\prime}-\frac{F(T ; q)}{T}\right]$, where the bracketed term is positive for all $\mathrm{r} \geq 0$. Thus the rotation age effect determines the sign of annual average timber supply.
} 
shortens rotation age, which decreases the average annual timber supply per parcel according to (28). Thus, the overall effect of price is ambiguous.

Ambiguity also surrounds the effect of the management cost parameter, $c$, on supplies. This lengthens rotation age and increases timber supply. However, because higher forest management costs shift land toward agriculture and toward illegal logging, the overall affect of $c$ on timber supply from sustainable managed land is unknown. Finally, as for the effect of the interest rate, both the margins and the rotation age change in response to this parameter, but in different directions. Thus, it is not clear how economy-wide interest rate changes affect supply from sustainable forests.

Any parameter that changes illegal logging will in principle also cause changes in timber supplies from sustainable forest land, via changes in the lower intensive margin. The effects of illegal logging parameters on sustainable timber supply are,

$$
\begin{aligned}
& \frac{d S_{f}}{d \tau}=-Q_{f}^{*}\left(q_{2}\right) \frac{\partial q_{2}}{\partial \tau}>0, \text { and } \\
& \frac{d S_{f}}{d \rho}=Q_{f}^{*}\left(q_{2}\right) \frac{\partial q_{2}}{\partial \rho}>0
\end{aligned}
$$

A higher penalty rate or probability of detection will increase timber supply from sustainable forests, due to increased land area devoted to sustainable forest production. This underscores again the need for developing countries to seriously enforce and protect forests from illegal logging if the goal is development of an economy based on supplies from sustainable uses of forest land.

Finally, for the effects of agricultural parameters on supply from the sustainable forest use, we can show that agricultural price increases will decrease timber supply, but increases in costs of either conversion or the agricultural input increase it. This again establishes a connection between policies that target agricultural costs and prices, and the land area subject to deforestation.

\subsection{Timber supply from unsustainable forestry}


Denote timber supply generated from (illegal) unsustainable exploitation of forests by $S_{m}$. The supply function for this use is defined as,

$$
S_{m}=\int_{\bar{q}}^{q_{2}} Q_{m}^{*}(q) g(q) d q
$$

where $Q_{m}^{*}(q)$ denotes the optimum value of $Q$ defined implicitly by (9). Differentiating (36) with respect to timber price, penalty rate and probability of detection gives,

$$
\begin{aligned}
& \frac{d S_{m}}{d \hat{p}_{f}}=\int_{\bar{q}}^{q_{2}} \frac{\partial Q_{m}^{*}}{\partial \hat{p}_{f}} g(q) d q+Q_{m}^{*}\left(q_{2}\right) \frac{\partial q_{2}}{\partial \hat{p}_{f}}-Q_{m}^{*}(\bar{q}) \frac{\partial \bar{q}}{\partial \hat{p}_{f}}=?, \\
& \frac{d S_{m}}{d \tau}=\int_{\bar{q}}^{q_{2}} \frac{\partial Q_{m}^{*}}{\partial \tau} g(q) d q+Q_{m}^{*}\left(q_{2}\right) \frac{\partial q_{2}}{\partial \tau}-Q_{m}^{*}(\bar{q}) \frac{\partial \bar{q}}{\partial \tau}<0, \text { and } \\
& \frac{d S_{m}}{d \rho}=\int_{\bar{q}}^{q_{2}} \frac{\partial Q_{m}^{*}}{\partial \rho} g(q) d q+Q_{m}^{*} \frac{\partial q_{2}}{\partial \rho}-Q_{m}^{*}(\bar{q}) \frac{\partial \bar{q}}{\partial \rho}<0 .
\end{aligned}
$$

A higher probability of detection or a higher penalty, both of which decrease expected rents from illegal logging, reduce supply from unsustainable forest use through corresponding changes in harvest intensity and land use. It has been suggested in the literature that timber price increases could provide a strong incentive for sustainable forest practice, but again we find that timber price is ambiguous and depends, as in (21), on the relative cost difference between illegal logging and sustainable forest management. This cost difference determines the effect of price on the lower intensive margin (second term in 37). If the costs of illegal logging are higher than costs of sustainable forest management, then we find a provocative result here, that supply from unsustainable illegal logging is increasing in the timber price. This follows from equation (37), where a higher price would work to increase supply from unsustainable logging through greater production intensity (first term), a higher lower intensive margin (second term), and a lower extensive margin (last term). 
The timber price effect is particularly interesting, because it confirms the idea that price-induced timber supply increases can work in the direction of increased harvest intensity and supply from unsustainable activities. This more general way of thinking follows in our model, because unsustainable logging competes with sustainable logging for land parcels.

In terms of comparative statics, we have some additional findings,

$$
\frac{d S_{m}}{d c}=Q_{m}^{*}\left(q_{2}\right) \frac{\partial q_{2}}{\partial c}>0 ; \frac{d S_{m}}{d \lambda}=Q_{m}^{*}\left(q_{2}\right) \frac{\partial q_{2}}{\partial \lambda}>0 ; \frac{d S_{m}}{d r}=Q_{m}^{*}\left(q_{2}\right) \frac{\partial q_{2}}{\partial r}=?
$$

Interestingly, higher costs of establishing sustainable forests or higher risk of confiscation for these forests increase supply from unsustainable forest use. This is consistent with the results we found earlier and they suggest, again, that policies or changes in parameters that affect sustainable forestry rents will spill over onto unsustainable forestry practices.

\subsection{Agricultural supply}

We close by briefly considering production intensity and supply from agricultural land use. Supply here is simply the sum of per parcel output supply for the area of land allocated to agriculture as follows:

$$
S_{a}=\int_{q_{1}}^{1} f^{*}(q) g(q) d q .
$$

In $(41), f^{*}(q)$ refers to the optimum level of agricultural production in any period when the agricultural input is employed at its optimal level, i.e., $f^{*}(q) \equiv f\left(\hat{l}^{*}\left(p_{a}, w, q\right) ; q\right)$ (see section 2.1). Differentiating (41) with respect to parameters characterizing sustainable forestry gives,

$$
\begin{aligned}
& \frac{d S_{a}}{d \hat{p}_{f}}=-f^{*}\left(q_{1}\right) \frac{\partial q_{1}}{\partial \hat{p}_{f}}<0 ; \frac{d S_{a}}{d c}=-f^{*}\left(q_{1}\right) \frac{\partial q_{1}}{\partial c}>0, \text { and } \\
& \frac{d S_{a}}{d \lambda}=-f^{*}\left(q_{1}\right) \frac{\partial q_{1}}{\partial \lambda}>0 ; \frac{d S_{a}}{d r}=-f^{*}\left(q_{1}\right) \frac{\partial q_{1}}{\partial r}=? .
\end{aligned}
$$


Agricultural supply decreases (increases) as timber price (management cost) increases via changes in land allocation and production intensities. Higher confiscation risk increases land conversion to agriculture, given that this use is more secure. Higher timber price reduces agricultural supply as more land is shifted toward sustainable forest production through changes in the upper intensive margin. Finally, a higher interest rate decreases supply from agricultural uses, but its affect on the upper intensive margin is ambiguous given that interest rate changes also negatively affect the profitability of sustainable forestry.

\section{Conclusions}

We developed a general model of all relevant land uses to analyze tropical deforestation in the presence of insecure property rights. We examined land use, production intensity, and supply by formalizing the margins between agricultural production (land clearing), sustainable forest management, and unsustainable forest exploitation in the form of illegal logging on frontier areas. Our analysis extends existing literature in many ways. First, we address all relevant land use alternatives, including both unsustainable and sustainable forest uses. Second, we introduce two important types of uncertainties surrounding property rights, which can differ across the forestry uses, and we link these uncertainties specifically to mechanisms of deforestation. Uncertainty arises through the possibility that forest rents can be confiscated before trees are harvested on land managed according to sustainable practices, and through a risk associated with illegal logging on the poorest quality land. The latter is a case where harvesters face some probability of being detected and fined by the government. Third, we link timber supply to deforestation mechanisms.

We examine the effects on land use and production intensity decisions of several important policy and market parameters, and in doing so uncover several new conclusions about the mechanisms of deforestation. Confiscation risk has serious effects on deforestation, through both land conversion to agriculture and through changes in the profitability of illegal logging relative to sustainable forest production. This risk also 
serves to reduce supplies from sustainable managed forests through changes in land use and through production intensity changes. The importance of higher timber prices to deforestation is much more complex than previous work suggests. Price effects depend on several important and measurable parameters such as interest rates, the difference in cost structure between illegal harvesting and the maintenance and harvesting of sustainable forests, and the magnitude of confiscation risk. Indeed, inclusion of the potential for illegal logging means that higher timber prices do not always lead to greater incentives for sustainable forest production. Rather, higher timber price could involve a shift of some sustainably-managed forest land to unsustainable logging and increase the illegal component of timber supply.

These new results and our extension to supply effects lead to several important policy conclusions. Clearly, anything a government can do to reduce the uncertainties will reduce deforestation. Reduction of confiscation risk works to reduce deforestation through a twin effect of reducing land conversion to agriculture and reducing incentives for illegal logging. As confiscation risk increases, supply from sustainable forest use decreases and supply from illegal logging increases. Working to increase monitoring of harvesting activities or committing to higher penalties for illegal logging will always reduce it, both directly and indirectly via reducing the expected profitability of illegal logging and shifting land toward sustainable forestry uses. Given our timber price findings, control of this parameter has unknown and often unintended consequences, both with respect to forest land use and timber supply. Governments would be wise to have good knowledge of the cost differences between sustainable and unsustainable practices before moving forward with reforms directed at prices. Finally, our complete land use model also shows that anything increasing the rents to agriculture serves to shift the margin of agricultural land toward poorer quality levels, displacing sustainable forest management. Thus, incentives for land clearing are not the only activities that poorlychosen agricultural subsidies encourage.

An interesting extension of the model would be to include the possibility of amenities on forest land of the two types in a social planner's problem, who must choose the optimal allocation of land in the different uses. Although amenities have been studied for native forests subject to exploitation in simpler models, it is worth nothing that 
amenities would become stochastic in our model owning to the fact that risk of confiscation or detection of illegal logging are present on sustainable and unsustainable forest land respectively. Possible starting points for this type of problem include models by Reed (1993) and Reed and Ye (1994). 


\section{References:}

Amacher, G., E. Koskela and M. Ollikainen. 2003. Optimal royalty design and illegal logging under alternative penalty schemes. University of Helsinki Department of Economics Discussion Paper DP-570.

Andersen, L., C. Granger, E. Reis, D. Weinhold, and S. Wunder. 2002. The Dynamics of Deforestation and Economic Growth in the Brazilian Amazon. Cambridge: Cambridge University Press.

Angelson, A. 1999. Agricultural expansion and deforestation: modeling the impact of population, market forces, and property rights. Journal of Development Economics 58:185-218

Angelson, A. and D. Kaimowitz. 1999. Rethinking the causes of deforestation: Lessons from economic models", The World Bank Research Observer 14:73-98.

Armsberg, J. 1998. Economic parameters of deforestation. World Bank Economic Review 12:133-153.

Barbier, E., N. Bockstael, J. Burgess, and I. Strand. 1995. The linkages between timber trade and tropical deforestation. The World Economy 18:411-442.

Barbier, E., and J. Burgess, 1997. The economics of tropical forest land use options. Land Economics 73:174-95.

Barreto, P., P. Amaral, E. Vidal, and C. Uhl. 1998. Costs and benefits of forest management for timber production in eastern Amazonia. Forest Ecology and Management 108:9-26.

Bohn, H., and R. Deacon. 2000. Ownership risk, investment, and the use of natural resources. American Economic Review 90:526-549.

Boscolo, M. and J. R. Vincent. 2000. Promoting Better Logging Practices in Tropical Forests: A Simulation Analysis of Alternative Regulations, Land Economics 76(1):1-14.

Clark, C.W. 1976. Mathematical Bioeconomics: The Optimal Management of Renewable Resources. New York: Wiley.

Clarke, H.R., W.J. Reed and R.M. Shestra. 1993. Optimal Enforcement of Property Rights on Developing Country Forests Subject to Illegal Logging, Resource and Energy Economics 15:271-293.

Conrad, J. 1999. Resource Economics. Cambridge: Cambridge University Press.

Deacon, R. 1994. Deforestation and the rule of law in a cross section of countries. Land Economics 70:414-430.

Gray, J. 2000. Forest concession Policies and revenue systems: Country experience and policy changes for sustainable tropical forestry. World Bank Technical Paper, Forest Series, Washington D.C.

Hardie, I. W. and Parks, P. J. 1997. Land use with heterogeneous land quality: an application of an area base model. American Journal of Agricultural Economics 77:299-310.

Hartwick, J., N. Van Long, and H. Tian et al. 2001. Deforestation and development in a small open economy. Journal of Environmental Economics and Management 41:235-251. 
Hyde, W., G. Amacher, and W. Magrath. 1996. Deforestation and forest land use: Theory, evidence, and policy implications. World Bank Research Observer 11:223-248.

International Tropical Trade Organization (ITTO). 2002. Forest crime: the midst clears. Tropical forest Update 12(1):1-9.

Khanna, M., M. Islik, and D. Zilberman. 2002. Cost effectiveness of alternative green payment policies for conservation technology adoption with heterogeneous land quality. Agricultural Economics 27:151-176.

Lichtenberg, E. 2002. Agriculture and the environment. In B. Gardner and G. Rausser (eds.) Handbook of Agricultural Economics. Vol 3B, Amsterdam: North-Holland, pp. 1249-1313.

Lichtenberg, E. 1989. Land quality, irrigation development, and cropping patterns in the Northern High Plains. American Journal of Agricultural Economics 71:187-194.

Mas-Colell, A., Whinston, M.D. and J.R. Green. 1995. Microeconomic Theory, Oxford: Oxford University Press.

Mendelsohn, R. 1994. Property rights and tropical deforestation. Oxford Economic Papers 46:750-756.

Parks, P., E. Barbier and J. Burgess. 1998. The Economics of forest use in temperate and tropical areas. Environmental and Resource Economics 11:473-487.

Pendleton, L. and L. Howe. 2002. Market integration, development, and smallholder forest clearance. Land Economics 78:1-19.

Reed, W. 1993. The decision to conserve or harvest an old growth forest. Ecological Economics 8:45-69.

Reed, W. 1984. The effects of the risk of fire on the optimal rotation of a forest. Journal of Environmental Economics and Management 11:180-190.

Reed, W., and J. Ye. 1994. The role of stochastic monotonicity in the decision to conserve or harvest an old growth forest. Natural Resource Modeling 8:47-79.

Winkler, N. 1997. Environmentally Sound Forest Harvesting: Testing the Applicability of the FAO Model Code in the Amazon of Brazil. Forest Harvesting Case Study 8. FAO, Rome. 
Figure 1. Land allocation as a function of land quality

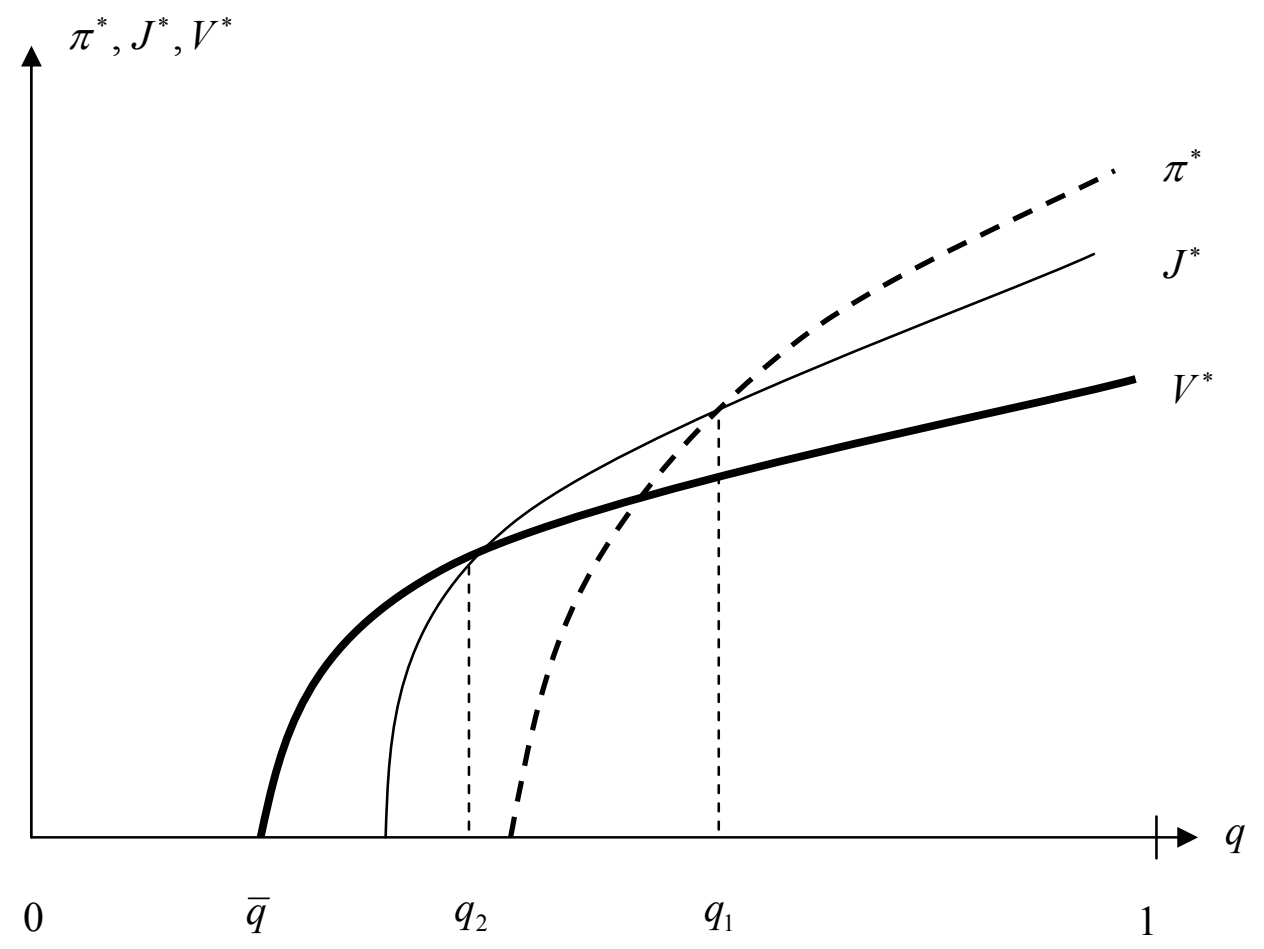




\section{APPENDIX 1: Optimal rotation with confiscation probability}

\section{A. Full confiscation}

Denote $x_{1}, \ldots, x_{n}$ as the times between successive confiscations of the stand. If the decision is to cut the stand whenever it reaches age, then the distribution of random variable explaining confiscation risk is $\Gamma(t)=1-e^{-\lambda t}$ for $t<T$ and $\Gamma(t)=1$ for $t \geq T$. Assuming that confiscation, when it occurs, is total, we can write the expected net present value of forests in sustainable production as

$J=E\left(\sum_{n=1}^{\infty} e^{-r\left(x_{1}+x_{2}+\ldots+x_{n}\right)} Y_{n}\right)$

where $Y_{n}=0$ if $x_{n}<T$ and $Y_{n}=p_{f} F(T ; q) e^{-r T}-c$ if $x_{n}=T$. Using the properties of Poisson process (A1.1) can be expressed as

$J=\sum_{n=1}^{\infty} \prod_{i=1}^{n-1} E\left(e^{-r x_{i}}\right) E\left(e^{-r x_{n}} Y_{n}\right)=\frac{E\left[e^{-r x}\left(p_{f} F(T ; q) e^{-r T}-c\right)\right]}{\left[1-E\left(e^{-r x}\right)\right]}$

Using $d \Gamma(t) / d t=\lambda e^{-\lambda t}$ we can then obtain the following expectations

$E\left(e^{-r x}\right)=\frac{\lambda+r e^{-(r+\lambda) T}}{r+\lambda} \quad$ and $\quad 1-E\left(e^{-r x}\right)=\frac{r\left(1-e^{-(r+\lambda) T}\right)}{r+\lambda}$

Substituting to RHSs of (A1.3) for $E\left(e^{-r x}\right)$ and $1-E\left(e^{-r x}\right)$ in equation (A1.2) yields

$J=\frac{(r+\lambda)\left[p_{f} F(T ; q) e^{-r T}-c\right] e^{-(r+\lambda) T}}{r\left(1-e^{-(r+\lambda) T}\right)}$

Writing now $F$ for $F(T ; q)$ to simplify notation, the first-order condition for the optimal rotation age is,

$J_{T}=0 \Leftrightarrow\left(1-e^{-(r+\lambda) T}\right)\left\lfloor p_{f}\left(F_{T}-r F\right) e^{-r T}\right]-(r+\lambda)\left[p_{f} F(T ; q) e^{-r T}-c\right\rfloor=0($

We assume that the second order condition holds, i.e.

$$
\begin{gathered}
J_{T T}=\left(1-e^{-(r+\lambda) T}\right)\left[p_{f}\left(F_{T T}-r F_{T}\right) e^{-r T}-r p_{f}\left(F_{T}-r F\right) e^{-r T}\right]-\left[(r+\lambda) p_{f} F e^{-r T}\right]+ \\
{\left[p_{f}\left(F_{T}-r F\right) e^{-r T}\right](r+\lambda) e^{-(r+\lambda) T}+(r+\lambda) r p_{f} F e^{-r T}<0}
\end{gathered}
$$




\section{Comparative statics}

Using the implicit function theorem, the effect of any parameter $\gamma$ on the optimal rotation age is written in general form as $T_{\gamma}=\left(-J_{T T}\right)^{-1} J_{T \gamma}$, so that $\operatorname{sign} T_{\gamma}=\operatorname{sign} J_{T \gamma}$. Now we can determine the effects of regeneration/maintenance cost and stumpage price as follows

$$
\begin{aligned}
& J_{T c}=(r+\lambda)>0 \Rightarrow T_{c}>0 \\
& J_{T \hat{p}_{f}}=\left(1-e^{-(r+\lambda) T}\right)\left(F_{T}-r F\right) e^{-r T}-(r+\lambda) F e^{-r T}<0 \Rightarrow T_{\hat{p}_{f}}<0
\end{aligned}
$$

In terms of the land quality parameter $q$ we have,

$$
J_{T q}=p_{f} e^{-r T}\left[\left(1-e^{-(r+\lambda) T}\right) F_{T q}-(r+\lambda) F_{q}\right\rfloor<0 \Rightarrow T_{q}<0
$$

The sign of (A1.9) holds because $F_{T q}<F_{q}$. Finally, for the probability of confiscation $\lambda$ we obtain

$$
J_{T \lambda}=T e^{-(r+\lambda) T}\left\lfloor p_{f}\left(F_{T}-r F\right) e^{-r T}\right\rfloor-\left\lfloor p_{f} F e^{-r T}-c\right\rfloor
$$

Using the first-order condition (A1.5) makes it possible to express the above expression as,

$J_{T \lambda}=\frac{p_{f}\left(F_{T}-r F\right) e^{-r T}}{r+\lambda}\left[(1+(r+\lambda) T) e^{-(r+\lambda) T}-1\right]$

The second-order approximation for the term $e^{-(r+\lambda) T} \approx\left[1+(r+\lambda) T+(1 / 2)(r+\lambda)^{2} T^{2}\right]^{-1}$ implies

$$
J_{T \lambda}=\frac{p_{f}\left(F_{T}-r F\right) e^{-r T}}{r+\lambda}\left[-\frac{(1 / 2)(r+\lambda)^{2} T^{2}}{1+(r+\lambda) T+(1 / 2)(r+\lambda)^{2} T^{2}}\right]<0 \Rightarrow T_{\lambda}<0\left(\mathrm{~A} 1.9{ }^{\prime},\right)
$$

Finally, differentiating (A1.5) with respect to $r$ gives

$$
\begin{gathered}
J_{T r}=-T\left(1-e^{-(r+\lambda) T}\right)\left[p_{f}\left(F_{T}-r F\right) e^{-r T}\right]-\left(1-e^{-(r+\lambda) T}\right)\left[p_{f}\left(F_{T}-r F\right) e^{-r T}\right]- \\
{\left[p_{f} F e^{-r T}-c\right]+(r+\lambda) T p_{f} F e^{-r T}}
\end{gathered}
$$


Denoting $\Delta=1-e^{-(r+\lambda) T}$ and $H=p_{f}\left(F_{T}-r F\right) e^{-r T}>0$ we can re-express the first-order condition (A1.5) as $\Delta H=(r+\lambda)\left[p_{f} F e^{-r T}-c\right]$ so that (A1.10) can be written as

$$
\begin{aligned}
J_{T r}= & -H\left[T(1+2 \Delta)+\frac{\Delta}{r+\lambda}\right]-e^{-r T} p_{f} F[\Delta-(r+\lambda) T]= \\
& -H\left[\frac{T(r+\lambda)-\Delta(1-\Delta)}{r+\lambda}\right]-c[\Delta-T(r+\lambda)]
\end{aligned}
$$

Now proceeding as before and using a second-order approximation for the term $e^{-(r+\lambda) T}$ we have $\frac{T(r+\lambda)-\Delta(1-\Delta)}{r+\lambda}>0$, while $\Delta-T(r+\lambda)<0$. Hence, if $c$ is small enough, then $J_{T r}<0 \Rightarrow T_{r}<0$.

\section{Properties of the indirect expected net present value function}

Substituting the optimal rotation age, $T^{*}=T\left(c, \hat{p}_{f}, q, \lambda, r\right)$, for $T$ in (A1.4) gives the indirect expected net present value function presented in the text, $J^{*}\left(c, \hat{p}_{f}, q, \lambda, r\right)$. Using the envelope theorem (see e.g. Mas-Colell et al. 1995, pp.964-966) we then have, (where we will write $T$ for the optimal level of rotation age $T^{*}$ in what follows),

$J_{c}^{*}=-\frac{(r+\lambda) e^{-(r+\lambda) T}}{r\left(1-e^{-(r+\lambda) T}\right)}<0$,

$J_{\hat{p}_{f}}^{*}=\frac{(r+\lambda) F e^{-r T} e^{-(r+\lambda) T}}{r\left(1-e^{-(r+\lambda) T}\right)}>0$, and

$J_{q}^{*}=\frac{(r+\lambda) p_{f} F_{q} e^{-r T} e^{-(r+\lambda) T}}{r\left(1-e^{-(r+\lambda) T}\right)}>0$, due to $F_{q}>0$.

Differentiating the indirect net present value function with respect to $\lambda$ gives, after some rearranging,

$J_{\lambda}^{*}=\left[r\left(1-e^{-(r+\lambda) T}\right)\right]^{-2} e^{-(r+\lambda) T}\left(p_{f} F e^{-r T}-c\right)\left(r\left(1-e^{-(r+\lambda) T}\right)-(r+\lambda) T\left(1+r e^{-(r+\lambda) T}\right)\right.$

The second-order approximation $e^{-(r+\lambda) T} \approx\left[1+(r+\lambda) T+(1 / 2)(r+\lambda)^{2} T^{2}\right]^{-1}$ gives $r\left(1-e^{-(r+\lambda) T}\right)-(r+\lambda) T\left(1+r e^{-(r+\lambda) T}\right)<0$, so that $J_{\lambda}^{*}<0$. Finally, differentiating 
the indirect net present value function with respect to $r$ and using the second-order approximation for $e^{-(r+\lambda) T}$ yields,

$$
J_{r}^{*}=\left[r\left(1-e^{-(r+\lambda) T}\right]^{-2}\left[\frac{1-\left(1+(r+\lambda) T+\left((1 / 2)(r+\lambda)^{2} T^{2}\right.\right.}{1+(r+\lambda) T+(1 / 2)(r+\lambda)^{2} T^{2}}\right]-p_{f} F e^{-r T}<0\right.
$$

\section{B.Partial confiscation}

If confiscation is partial, then the term $Y_{n}$ in the expected net present value of forests in sustainable production (A1.1) can be written as,

$$
Y_{n}=\left\{\begin{array}{l}
k p_{f} F(T ; q) e^{-r T} \quad \text { if } \quad x_{n}<T \\
p_{f} F(T ; q) e^{-r T}-c \quad \text { if } \quad x_{n}=T
\end{array}\right.
$$

where $0<k<1$ is the proportion of non-confiscation. Using a similar procedure as earlier, we can write the expected net present value of forests in sustainable production in the presence of partial confiscation as

$$
\widehat{J}=J+k \frac{\lambda p_{f} F(T ; q) e^{-r T}}{r}
$$

where $J$ has been written in (A1.4). The first-order condition for the optimal rotation age is now,

$$
\widehat{J}_{T}=J_{T}+k \frac{\lambda p_{f}\left(F_{T}-r F\right) e^{-. r T}}{r}=0
$$

where $J_{T}$ has been written in (A1.5). Assuming that the second-order condition holds and using the implicit function theorem we obtain $T_{k}=\left(-\widehat{J}_{T T}\right)^{-1} \widehat{J}_{T k}>0$, where

$$
\widehat{J}_{T k}=\frac{\lambda p_{f}\left(F_{T}-r F\right) e^{-r T}}{r}>0
$$

Substituting the optimal rotation age, $T^{*}=T\left(c, p_{f}, q, \lambda, r, k\right)$, for $T$ in (A1.17) gives the indirect expected net present value function $\widehat{J}^{*}\left(c, p_{f}, q, \lambda, r, k\right)$. Using the envelope theorem we obtain, 


$$
\widehat{J}_{k}^{*}=\frac{\lambda p_{f} F(T ; q) e^{-r T}}{r}>0
$$

\section{APPENDIX 2. Comparative Statics of Land Allocation}

The effect of exogenous variables emerges via the changes of upper and lower intensive margin and via changes in the external margin. In this appendix we solve for expressions of how the margins change for a change in the general parameter vector $\theta$ defined in the text, i.e., $\frac{\partial q_{1}}{\partial \theta}, \frac{\partial q_{2}}{\partial \theta}$ and $\frac{\partial \bar{q}}{\partial \theta}$ for the upper intensive, lower intensive, and extensive margins, respectively.

A. Upper intensive margin $\left(\frac{\partial q_{1}}{\partial \theta}\right)$.

Totally differentiating condition (12) defining the margin, $\pi^{*}-J^{*}=0$, we obtain $J_{\hat{p}_{f}}^{*} d \hat{p}_{f}+J_{c}^{*} d c+J_{\lambda}^{*} d \lambda-\pi_{p_{a}}^{*} d p_{a}-\pi_{\psi}^{*} d \psi-\pi_{w}^{*} d w+\left(J_{r}^{*}-\pi_{r}^{*}\right) d r+\left(J_{q}^{*}-\pi_{q}^{*}\right) d q_{1}=0$

Defining $D=\left(\pi_{q_{1}}^{*}-J_{q_{1}}^{*}\right)>0$, evaluated at the upper intensive margin, we then have,

$$
\begin{aligned}
& \frac{\partial q_{1}}{\partial \hat{p}_{f}}=\frac{J_{\hat{p}_{f}}^{*}}{D}>0 ; \frac{\partial q_{1}}{\partial c}=\frac{J_{c}^{*}}{D}<0 ; \frac{\partial q_{1}}{\partial \lambda}=\frac{J_{\lambda}^{*}}{D}<0 ; \frac{\partial q_{1}}{\partial p_{a}}=-\frac{\pi_{p a}^{*}}{D}<0 ; \frac{\partial q_{1}}{\partial \psi}=-\frac{\pi_{\psi}^{*}}{D}>0 ; \\
& \frac{\partial q_{1}}{\partial w}=-\frac{\pi_{w}^{*}}{D}>0 ; \frac{\partial q_{1}}{\partial r}=\frac{\pi_{r}^{*}-J_{r}^{*}}{D}=? .
\end{aligned}
$$

B. Lower intensive margin $\left(\frac{\partial q_{2}}{\partial \theta}\right)$

Totally differentiating condition (13) and defining the margin, $V^{*}-J^{*}=0$, yields

$$
\left(V_{\hat{p}_{f}}^{*}-J_{\hat{p}_{f}}^{*}\right) d \hat{p}_{f}-J_{c}^{*} d c-J_{\lambda}^{*} d \lambda+V_{\tau}^{*} d \tau+V_{\rho}^{*} d \rho-\pi_{w}^{*} d w+\left(V_{r}^{*}-J_{r}^{*}\right) d r+\left(V_{q}^{*}-J_{q}^{*}\right) d q_{1}=0 .
$$

Denoting $\left(V_{q}^{*}-J_{q}^{*}\right)=\Delta<0$, evaluated at the lower intensive margin, we obtain the following results,

$$
\begin{aligned}
& \frac{\partial q_{2}}{\partial \hat{p}_{f}}=-\frac{V_{\hat{p}_{f}}^{*}-J_{\hat{p}_{f}}^{*}}{\Delta}=? ; \frac{\partial q_{2}}{\partial c}=\frac{J_{c}^{*}}{\Delta}>0 ; \frac{\partial q_{2}}{\partial \lambda}=\frac{J_{\lambda}^{*}}{\Delta}>0 ; \frac{\partial q_{2}}{\partial \tau}=-\frac{V_{\tau}^{*}}{\Delta}<0 ; \frac{\partial q}{\partial \rho}=-\frac{V_{\rho}^{*}}{\Delta}<0 ; \\
& \frac{\partial q_{2}}{\partial r}=-\frac{V_{r}^{*}-J_{r}^{*}}{\Delta}=? \\
& \text { C. Extensive margin }\left(\frac{\partial \bar{q}}{\partial \theta}\right)
\end{aligned}
$$


Differentiating totally the condition (14) defining this margin, $V^{*}=0$, yields

$$
\frac{\partial \bar{q}}{\partial \hat{p}_{f}}=-\frac{Q(1-\rho \tau)}{V_{q}^{*}}<0 ; \frac{\partial \bar{q}}{\partial \tau}=\frac{\rho \hat{p}_{f} Q}{V_{q}^{*}}>0 ; \frac{\partial \bar{q}}{\partial \rho}=\frac{\tau \hat{p}_{f} Q}{V_{q}^{*}}>0 .
$$

\section{Unsustainable forestry land allocation}

The effects of parameters on land devoted to unsustainable forest practice are given by,

$$
\frac{d L_{m}}{d c}=g\left(q_{2}\right) \frac{J_{c}^{*}}{\Delta}>0 ; \frac{d L_{m}}{d \lambda}=g\left(q_{2}\right) \frac{J_{\lambda}^{*}}{\Delta}>0 ; \frac{d L_{m}}{d r}=-g\left(q_{2}\right) \frac{V_{r}^{*}-J_{r}^{*}}{\Delta}=?
$$

\section{E. Agricultural supply}

$$
\begin{aligned}
& \frac{d S_{a}}{d p_{a}}=\int_{q_{1}}^{1} f_{l}^{*}(.) \frac{\partial l}{\partial p_{a}} g(q) d q-f^{*}\left(q_{1}\right) \frac{\partial q_{1}}{\partial p_{a}}>0, \\
& \frac{d S_{a}}{d w}=\int_{q_{1}}^{1} f_{l}^{*}(.) \frac{\partial l}{\partial w} g(q) d q-f^{*}\left(q_{1}\right) \frac{\partial q_{1}}{\partial w}<0, \text { and } \\
& \frac{d S_{a}}{d \psi}=-f^{*}\left(q_{1}\right) \frac{\partial q_{1}}{\partial \psi}<0 .
\end{aligned}
$$

